\title{
$\beta$-Adrenoceptor stimulation and neutrophil accumulation in mouse airways
}

\author{
M. Miyamoto, M. Tomaki, J. Lötvall, A. Lindén
}

$\beta$-Adrenoceptor stimulation and neutrophil accumulation in mouse airways M. Miyamoto, M. Tomaki, J. Lötvall, A. Lindén. (C) ERS Journals Ltd 2004.

ABSTRACT: This study characterised the effect of $\beta$-adrenoceptor stimulation on endotoxin-induced accumulation of neutrophilic granulocytes in mouse airways, where the cytokines interleukin (IL)-6 and macrophage inflammatory protein (MIP)-2 are involved as mediators.

The $\beta_{2}$-adrenoceptor agonist salbutamol (0.025-250 $\left.\mathrm{fMol}\right)$ was administered intranasally in mice $24 \mathrm{~h}$ prior to administration of endotoxin $(10 \mu \mathrm{g})$ intranasally. Bronchoalveolar lavage (BAL) fluid and venous blood, respectively, was harvested (6 or $24 \mathrm{~h})$ after administration of endotoxin.

Salbutamol substantially decreased the number of neutrophils in BAL fluid from endotoxin-exposed (6 and $24 \mathrm{~h})$ mice and this effect was dose dependent $(24 \mathrm{~h})$. Pretreatment with the $\beta$-adrenoceptor antagonist propranolol attenuated the inhibitory effect of salbutamol on BAL neutrophils (6 and $24 \mathrm{~h})$, an attenuation that was not due to any unspecific effect of propranolol. Salbutamol also substantially decreased IL-6, but not MIP-2 in BAL fluid $(6 \mathrm{~h})$. In contrast to BAL fluid, salbutamol caused a moderate increase in blood neutrophils $(24 \mathrm{~h})$.

In conclusion, as indicated in mouse airways in vivo, $\beta$-adrenoceptor stimulation prior to endotoxin exposure inhibits the induced accumulation of neutrophils at a time point much later than that anticipated from its bronchodilatory effect. Even though the detailed molecular mechanisms behind this sustained "anti-inflammatory" effect remain unknown, it seems likely that this effect is in part due to a decrease in the local concentration of interleukin-6.

Eur Respir J 2004; 24: 231-237.
Lung Pharmacology Group, Dept of Respiratory Medicine and Allergology, Institute of Internal Medicine, University of Göteborg, Gothenburg, Sweden.

Correspondence: A. Lindén, Cooperative Research Centre - CID, Dept Pharmacology and Medicine, University of Melbourne, Medical Building, Level 8, W810, Grattan/Royal Parade, Parkville, VIC 3010, Australia.

Fax: 61383440241

E-mail: anders.linden@1ungall.gu.se

Keywords: Bronchoalveolar lavage, interleukin6 , macrophage inflammatory protein-2, neutrophilic granulocytes, propanolol, salbutamol

Received: March 232004

Accepted: March 252004

This study was financially supported by the Swedish Heart-Lung Fund, the Swedish Research Council (K2000-71X-090408-11A), the Vardal Foundation in Sweden and GlaxoSmithKline, UK. No support, direct or indirect, was obtained from the tobacco industry.
Several clinical studies indicate an association between an accumulation of neutrophilic granulocytes in the airways and severe, noninfectious exacerbations of obstructive pulmonary diseases, such as asthma and chronic obstructive pulmonary disease (COPD) [1]. Because of this, the prevention of an exaggerated accumulation of neutrophils may constitute a useful pharmacotherapeutical strategy, with a beneficial effect on severe exacerbations of asthma and COPD.

Bronchodilation by stimulation of $\beta_{2}$-adrenoceptors is a frequently utilised therapy in patients with obstructive pulmonary disease. In spite of the frequent clinical use of this therapy, it remains unclear whether or not $\beta_{2}$-adrenoceptor stimulation as monotherapy causes pro- or anti-inflammatory effects in the airways. Clinical evidence in support of such a pro-inflammatory effect includes data showing that regular inhalation of the $\beta_{2}$-adrenoceptor agonist salbutamol worsens exercise and allergen-induced bronchoconstriction in patients with asthma [2-4]. Similarly, regular inhalation of the $\beta_{2}$-adrenoceptor agonist terbutaline increases eosinophilic granulocytes in induced sputum from patients with atopic asthma [5]. There are no published clinical data on the involvement of neutrophils in this respect but one study on rodents in vivo indicates that endogenous stimulation of $\beta$-adrenoceptors contributes to the mobilisation of blood neutrophils following systemic exposure to platelet activating factor [6]. Interestingly, there is also evidence from human airway smooth muscle cells, bronchial epithelial cells and monocytes in vitro that stimulation of $\beta$ adrenoceptors per se increases the release of interleukin (IL)8 , one of the most potent neutrophil chemoattractants in humans [7-11]. However, $\beta$-adrenoceptor stimulation does decrease the induced release of the neutrophil-mobilising cytokines granulocyte-macrophage colony-stimulating factor (GM-CSF) and IL-6 in vitro, in human airway smooth muscle and macrophage-like cells, respectively $[12,13]$.

The aim of the current study was to characterise the effect of $\beta$-adrenoceptor stimulation on endotoxin-induced accumulation of neutrophils in the airways in vivo. To do this, the $\beta_{2}$-adrenoceptor agonist salbutamol was administered once, $24 \mathrm{~h}$ prior to endotoxin exposure in the airways of mice in vivo and cell differential counts as well as the concentration of the neutrophil-mobilising cytokines IL-6 and macrophage inflammatory protein-2 (MIP-2), a murine IL-8 correlate, in bronchoalveolar lavage (BAL) fluid, harvested 6 and $24 \mathrm{~h}$ after endotoxin exposure [14-20], were subsequently assessed.

\section{Methods}

\section{Animals}

The current study used pathogen-free male C57BL/6 mice (aged 6-8 weeks, weight range 21-26 g; B\&K Universal AB, Stockholm, Sweden). Mice were kept in individually ventilated 
racks and received standard laboratory food plus water ad libidum at the Animal Care Facility of Göteborg University. The experiments were approved by the Animal Ethics Committee in Göteborg, Sweden (DNo. 310/98).

\section{Anaesthesia and euthanisation}

Prior to intranasal (i.n.) administration of endotoxin and salbutamol, or intraperitoneal (i.p.) administration of propranolol, or respective vehicles (see below), mice were transiently anesthetised using $\mathrm{CO}_{2}$ gas (AGA Gas $\mathrm{AB}$, Göteborg, Sweden) in a sealed chamber as previously described [18]. By the end of each experiment and prior to the collection of BAL and blood samples, the animals were anaesthetised using a mixture of xylazin $\left(130 \mathrm{mg} \cdot \mathrm{kg}^{-1}\right.$ in $0.1 \mathrm{~mL}$ sterile phosphate-buffered saline (PBS)) and ketamine $\left(670 \mathrm{mg} \cdot \mathrm{kg}^{-1}\right.$ in $0.1 \mathrm{~mL}$ PBS) (Apoteksbolaget, Göteborg, Sweden) i.p. After reaching a deep level of anaesthesia, the mice were euthanised through opening of the chest and bleeding of the right ventricle of the heart.

\section{Endotoxin exposure}

Endotoxin (LPS $10 \mu \mathrm{g}$, Escherichia coli Serotype 055:B5, Sigma, St Lous, MO, USA) or its vehicle (PBS $25 \mu \mathrm{l}$ ) was administrated i.n. [8, 18]. This dose of endotoxin causes a submaximum increase in the number of BAL neutrophilic granulocytes $24 \mathrm{~h}$ later in the mouse model [18]. The referred increase in neutrophils is accompanied by a corresponding increase in mouse IL-6 and MIP-2 in BAL fluid and it is attenuated by pretreatment with antibodies against mouse IL6 and MIP-2 [18].

\section{$\beta_{2}$-adrenoceptor stimulation}

The $\beta_{2}$-adrenoceptor agonist salbutamol $(25 \mu \mathrm{L}$ of 0.01-10 nM salbutamol hydrochloride, Sigma Chemicals Co., St Louis, MO, USA) or corresponding vehicle (PBS) was administered i.n. $24 \mathrm{~h}$ prior to endotoxin exposure.

\section{$\beta$-adrenoceptor blockade}

Propranolol $\left(10 \mathrm{mg} \cdot \mathrm{kg}^{-1}\right.$ of propranolol hydrochloride, Sigma) or its vehicle $(0.5 \mathrm{~mL}$ PBS $)$ was administrated i.p. $2 \mathrm{~h}$ prior to salbutamol during aneasthesia obtained using carbon dioxide. After injection of propranolol, air $(0.2 \mathrm{~mL})$ was flushed through the i.p. needle to ascertain intraabdominal delivery of the drug solution.

\section{Bronchoalveolar lavage}

After tracheotomy, BAL was performed twice by instilling PBS $(0.25 \mathrm{~mL})$ through the tracheal cannula, followed by gentle aspiration. The fluid from the two BAL procedures was pooled and kept on ice until further processing. The BAL recovery volume was $\sim 80 \%$ of the instilled fluid in all treatments groups. After retrieval, the BAL fluid was centrifuged at $1,000 \mathrm{rpm}$ during $10 \mathrm{~min}$ at $4^{\circ} \mathrm{C}$ (Eppendorf, Netheler, Germany), and the cell pellet was then resuspended in washing buffer $(0.03 \%$ bovine serum albumin in PBS, Sigma).

\section{Blood samples}

All blood samples $(0.6 \mathrm{~mL})$ were harvested from the right ventricle of the heart during the final anaesthesia (see above).

\section{Cell differential counts}

The total cell numbers (i.e. concentrations) were determined in a haematocytometer after staining of cells with Türk solution. Differential cell counts were performed on cytospin preparations (Cytospin 3; Shandon Life Science, Astmor, UK) using May-Grünwald-Giemsa staining and oil immersion microscopy (Zeiss Axioplan 2; Carl Zeiss, Jena, Germany). Cell counts were carried out on 400 cells in BAL samples and on 200 cells in blood samples.

\section{Cytokine measurements}

Cell-free BAL fluid was collected and stored at $-84^{\circ} \mathrm{C}$. These samples were analysed without any concentration procedure, using commercial ELISA kits for mouse IL-6 and MIP-2 (Quantikine; R\&D Systems Europe Ltd). The detection limits were 15.6 and $7.8 \mathrm{pg} \cdot \mathrm{mL}^{-1}$, respectively, for these assays.

\section{Data analysis}

All descriptive statistics are presented as mean \pm SE. For statistical analysis of differences between two treatment groups, an unpaired t-test was used. For statistical analysis of differences between multiple treatment groups, analysis of variance followed by Fischer's prevented least significant difference was used. Correlations were evaluated using Spearman's rank correlation test. $\mathrm{N}$ equals the number of independent observations (animals). Statistical significance was from $\mathrm{p}<0.05$.

\section{Results}

\section{$\beta$-adrenoceptor stimulation and neutrophils in naive mice}

Treatment with salbutamol i.n. 24 h prior to PBS exposure (vehicle of endotoxin) i.n. decreased the number of neutrophils in BAL fluid harvested $24 \mathrm{~h}$ after PBS exposure (fig. 1a). In contrast, treatment with salbutamol i.n. increased the percentage of neutrophils in venous blood at the same time point (fig. 1b).

\section{$\beta$-adrenoceptor stimulation and neutrophils in endotoxin- exposed mice}

Endotoxin exposure i.n. substantially increased the number of neutrophils in BAL fluid harvested $24 \mathrm{~h}$ later (fig. 2a). Treatment with salbutamol i.n. $24 \mathrm{~h}$ prior to endotoxin exposure attenuated this increase in BAL neutrophils in a dose-dependent and substantial fashion within the dose range 0.025-2.5 fMol (fig. 2a).

Endotoxin exposure i.n. also tended to increase the percentage of neutrophils in venous blood harvested $24 \mathrm{~h}$ later, even though this effect was not statistically significant (fig. 2b). However, treatment with salbutamol i.n. $24 \mathrm{~h}$ prior to endotoxin exposure caused a clear increase in the percentage of blood neutrophils at the lowest tested dose of salbutamol; even though this effect did not seem to be increasing with dose (fig. 2b). 

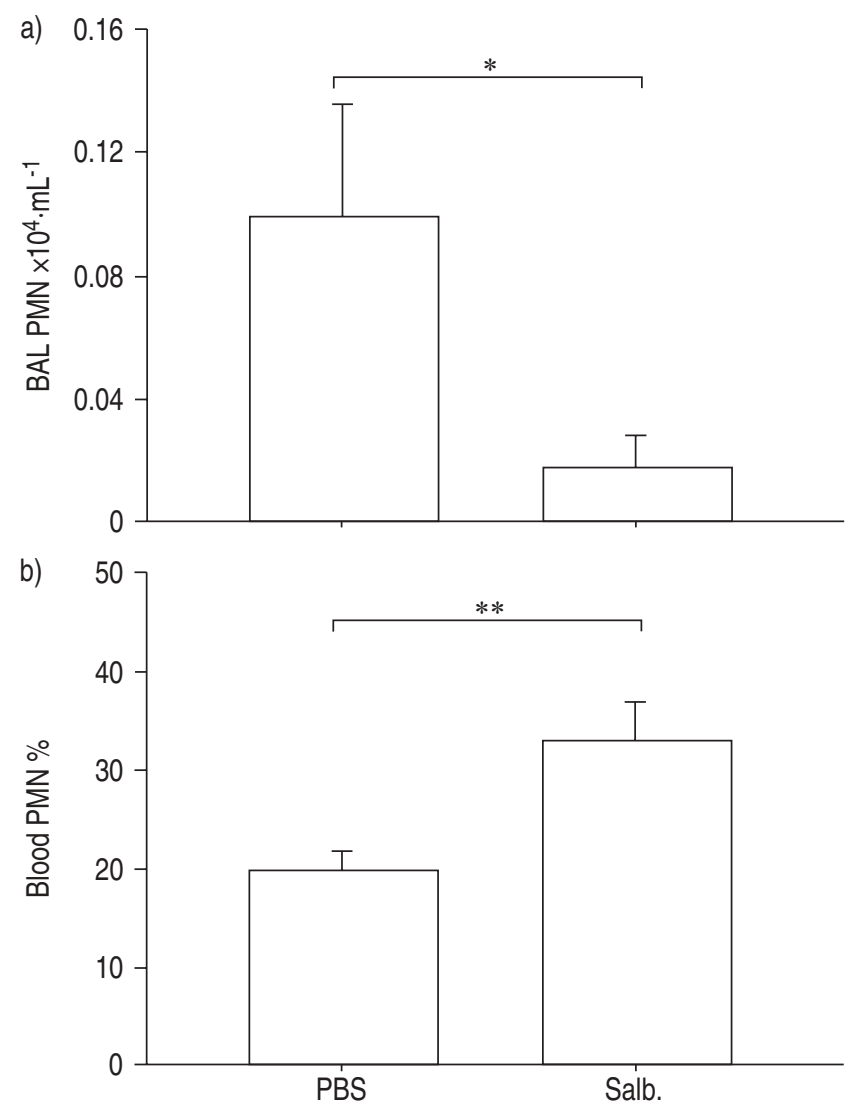

Fig. 1.-Effect of intranasal treatment with the $\beta_{2}$-adrenoceptor agonist salbutamol (salb.) (250 fMol) compared with its vehicle (25 $\mu \mathrm{L}$ phosphate-buffered saline (PBS)), on a) the number of neutrophilic granulocytes (PMN) in bronchoalveolar lavage (BAL) fluid and $b$ ) the percentage of neutrophils in venous blood (harvested from the right ventricle of the heart) in naive mice (C57BL/6). BAL fluid and venous blood was collected $24 \mathrm{~h}$ after treatment with salbutamol or its vehicle. Data are presented as mean with error bars showing SE. *: $\mathrm{p}<0.05 ; * *: \mathrm{p}<0.01 . \mathrm{n}=10$.

\section{$\beta$-adrenoceptor blockade and neutrophils in $\beta_{2}$-adrenoceptor stimulated and endotoxin-exposed mice}

Pretreatment with the $\beta$-adrenoceptor antagonist propranolol i.p. attenuated the inhibitory effect of salbutamol on the increase in BAL neutrophils following endotoxin exposure. This pattern was observed regardless whether the BAL fluid was harvested 6 or $24 \mathrm{~h}$ after endotoxin exposure (fig. $3 a$ and $b$ respectively). In mice exposed to endotoxin but not salbutamol, pretreatment with propranolol alone tended to lower the BAL neutrophil number (down to $15.2(3.7) \times 10^{4} \mathrm{~mL}^{-1} ; \mathrm{n}=29$ ), compared with mice pretreated with the vehicle of propanolol alone (fig. 3b).

In contrast to its effect on BAL neutrophils, pretreatment with the $\beta$-adrenoceptor antagonist propranolol did not markedly alter the percentage of neutrophils in venous blood harvested $24 \mathrm{~h}$ after endotoxin exposure from mice treated with salbutamol (fig. 4).

\section{$\beta$-adrenoceptor stimulation and cytokines in endotoxin- exposed mice}

Endotoxin exposure i.n. caused a marked increase in the concentration of IL-6 in BAL fluid harvested $6 \mathrm{~h}$ or $24 \mathrm{~h}$ later
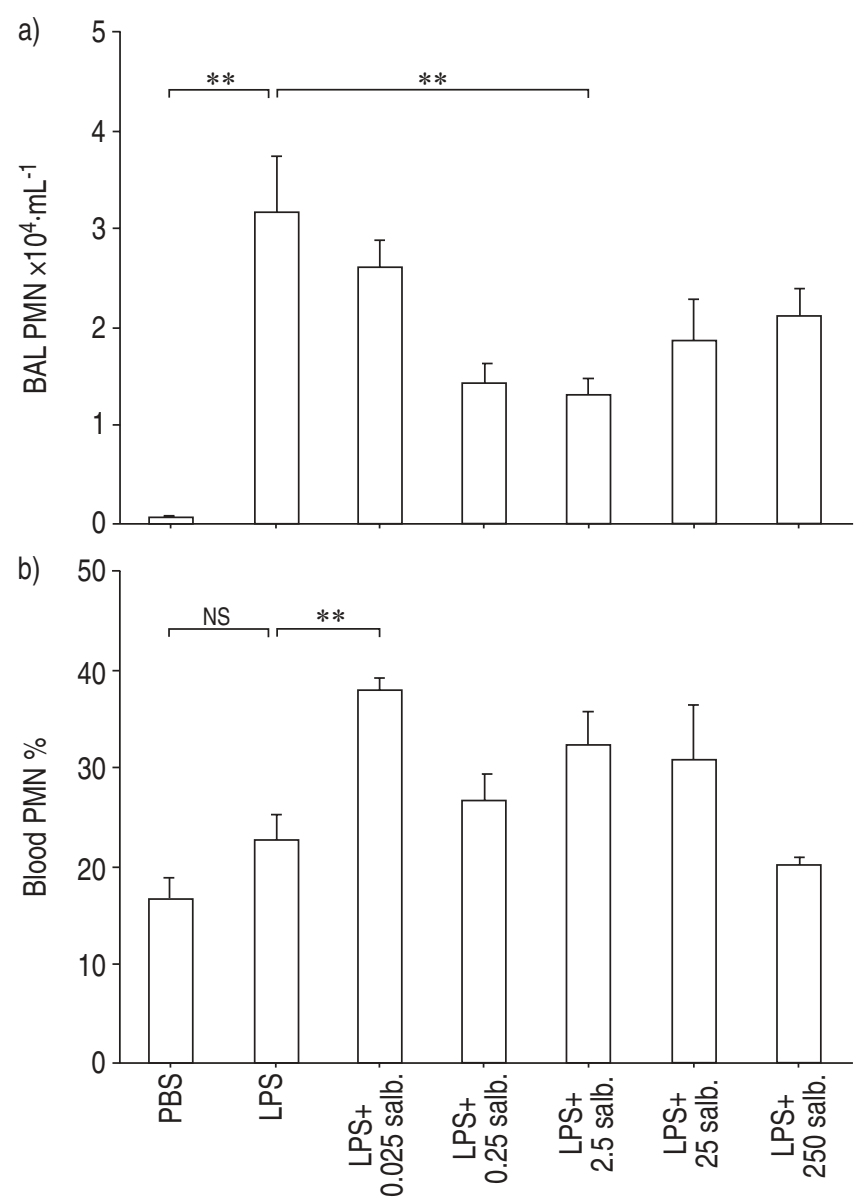

Fig. 2. - Effect of treatment with various doses of intranasal salbutamol (salb.) compared with its vehicle $(25 \mu \mathrm{L}$ phosphate buffered saline (PBS)), administered prior to subsequent exposure to endotoxin (LPS; $10 \mu \mathrm{g})$ or its vehicle $(25 \mu \mathrm{L}$ PBS), on a) the number of neutrophils (PMN) in bronchoalveolar lavage (BAL) fluid (Rho=-0.4, $\mathrm{p}<0.05$ according to Spearman rank correlation test; $n=40$ ) and b) the percentage of neutrophils (PMN) in venous blood in mice. BAL fluid and blood was collected $24 \mathrm{~h}$ after exposure to endotoxin. Data are presented as mean with error bars showing SE. NS: nonsignificant. **: $\mathrm{p}<0.01$. $\mathrm{n}=10$ for PBS, LPS +0.025 salb., LPS +25 salb. and LPS +250 salb. $\mathrm{n}=15$ for LPS, LPS +0.25 salb. and LPS +2.5 salb.

(fig. 5a and $\mathrm{b}$ respectively). Treatment with salbutamol attenuated this increase in IL-6 at $6 \mathrm{~h}$ after endotoxin exposure (fig. 5a). A similar trend was observed at $24 \mathrm{~h}$ after endotoxin exposure (fig. 5b) but it failed to prove statistically significant. Pretreatment with the $\beta$-adrenoceptor antagonist propranolol attenuated the inhibitory effect of salbutamol on the referred increase in IL-6 at $6 \mathrm{~h}$ (fig. 5a) but did not cause any statistically significant effect at $24 \mathrm{~h}$ (fig. 5b) after endotoxin exposure.

Endotoxin exposure i.n. also increased the concentration of MIP-2 in BAL fluid harvested 6 and 24 h later (fig. $6 a$ and b respectively). However, treatment with salbutamol did not attenuate this increase in MIP-2; neither $6 \mathrm{~h}$ or $24 \mathrm{~h}$ after endotoxin exposure (fig. $6 \mathrm{a}$ and $\mathrm{b}$ respectively). Pretreatment with the $\beta$-adrenoceptor antagonist propranolol did not markedly alter the MIP-2 concentration at either time point (fig. $6 \mathrm{a}$ and $\mathrm{b}$, respectively).

As measured $6 \mathrm{~h}$ after endotoxin exposure, the concentration of IL-6 and number of neutrophils in BAL fluid displayed a strong correlation (fig. 7a), whereas this was not the case for the concentration of MIP-2 and the number of neutrophils (fig. 7b). There was no corresponding correlation at $24 \mathrm{~h}$ after endotoxin exposure (data not shown). 

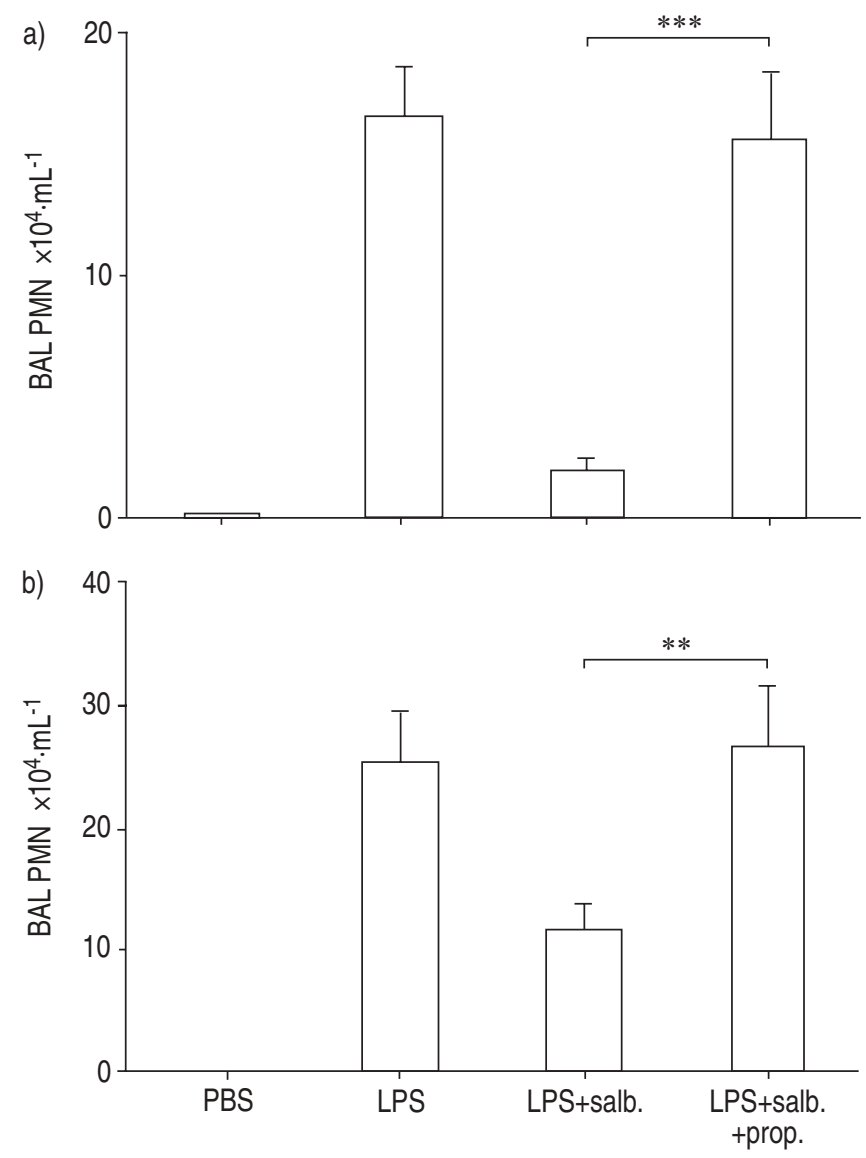

Fig. 3. - Effect of pretreatment intraperitoneally with the $\beta$-adrenoceptor antagonist propranolol (prop.; $\left.50 \mathrm{mg} \cdot \mathrm{kg}^{-1}\right)$ or its vehicle $(0.5 \mathrm{~mL}$ phosphate-buffered saline (PBS)), prior to treatment with salbutamol (salb.; $2.5 \mathrm{fMol}$ ) or its vehicle (25 $\mu \mathrm{L}$ PBS) intranasally (i.n.), followed by subsequent exposure to endotoxin (LPS; $10 \mu \mathrm{g}$ ) or its vehicle $(25 \mu \mathrm{L}$ PBS) i.n. on the concentration of neutrophils (PMN) in bronchoalveolar lavage (BAL) fluid in mice. BAL fluid was collected a) $6 \mathrm{~h}$ and b) $24 \mathrm{~h}$ after endotoxin exposure. Data presented as mean with error bars showing SE. **: $\mathrm{p}<0.01$; ***: $\mathrm{p}<0.001 . \mathrm{n}=10$ (a). $\mathrm{n}=17$ for PBS, $\mathrm{n}=30$ for LPS and LPS+salb., $\mathrm{n}=28$ for LPS+salb.+prop (b).

\section{Discussion}

This study on mouse airways in vivo shows that one treatment intranasally with the $\beta_{2}$-adrenoceptor agonist salbutamol, within a certain dose interval and $24 \mathrm{~h}$ prior to endotoxin exposure, does prevent the induced increase in BAL neutrophils harvested at up to $24 \mathrm{~h}$ after endotoxin exposure. The study also shows that salbutamol's action on the number of BAL neutrophils is attenuated by pretreatment intraperitoneally with the nonselective $\beta$-adrenoceptor antagonist propranolol, whereas propranolol per se does decrease BAL neutrophils in endotoxin treated mice; this rules out an unspecific increasing effect of propranolol per se on BAL neutrophils. Thus, collectively, these findings indicate that local $\beta$-adrenoceptor stimulation prevents the accumulation of airway neutrophils caused by a pathogenetically relevant stimulus and that this effect is sustained. Because the decrease in BAL neutrophils was also observed in naive, unexposed mice, this effect may be independent of stimulus. This potentially anti-inflammatory action appears to require moderate doses of the $\beta$-adrenoceptor agonist, compared to what is given to human patients, even when difference in body weight is accounted for [21].

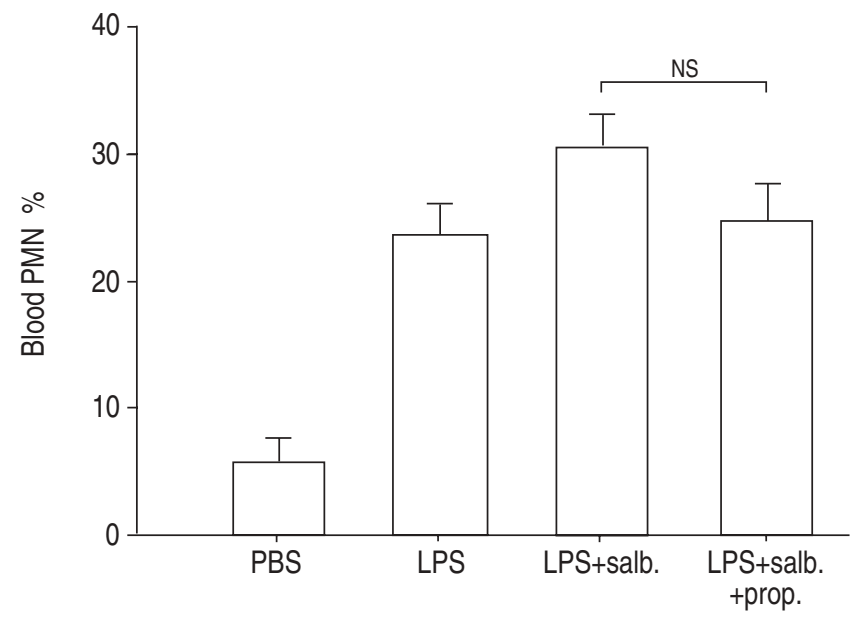

Fig. 4.-Effect of pretreatment intraperitoneally with propranolol (prop.; $\left.50 \mathrm{mg} \cdot \mathrm{kg}^{-1}\right)$ or its vehicle $(0.5 \mathrm{~mL}$ phosphate-buffered saline (PBS)), prior to treatment with salbutamol (salb.; $2.5 \mathrm{fMol}$ ) or its vehicle $(25 \mu \mathrm{L}$ PBS) intranasally (i.n.), followed by subsequent exposure i.n. to endotoxin (LPS; $10 \mu \mathrm{g}$ ) or its vehicle ( $25 \mu \mathrm{L}$ PBS), on the percentage of neutrophils (PMN) in venous blood from mice. Venous blood was harvested $24 \mathrm{~h}$ after endotoxin exposure. Data presented as mean with error bars showing SE. NS: nonsignificant. $\mathrm{n}=17$ for PBS, $\mathrm{n}=30$ for LPS and LPS+salb., $\mathrm{n}=28$ for LPS+salb.+prop.

In order to further characterise its mechanism of action, the current authors also determined salbutamol's effect on the concentration of IL-6 and MIP-2 in BAL fluid; two cytokines that are involved in determining the recruitment, activation and survival of neutrophils [14-20]. The current authors found that when the utilised $\beta$-adrenoceptor agonist is administrated $24 \mathrm{~h}$ prior to endotoxin, it inhibits the endotoxin-induced increase in IL-6 $6 \mathrm{~h}$ later (and thus $30 \mathrm{~h}$ after administration of salbutamol). This is not true for the IL-8 correlate MIP-2. In contrast, the current authors observed a weak trend towards an increase in the IL-8 correlate MIP-2 at the same time point, in line with previously published data on IL-8 release in bronchial epithelial cells [9, 11]. The current authors also found that the $\beta$-adrenoceptor antagonist propranolol attenuates salbutamol's inhibitory effect on IL-6. When assessed $24 \mathrm{~h}$ after endotoxin (and thus $48 \mathrm{~h}$ after the administration of salbutamol) the utilised $\beta$ adrenoceptor agonist did not display any significant inhibitory effect on either IL-6 or MIP-2. The current authors also observed that local IL-6 displays a strong correlation with neutrophils in BAL suspension, as measured $6 \mathrm{~h}$ after endotoxin exposure. In contrast, this is not the case for MIP-2. No corresponding correlation with BAL neutrophils $24 \mathrm{~h}$ after endotoxin exposure, neither for IL-6 nor for MIP2 , was detected. Unfortunately, the experimental system did not allow assessment of any putative, corresponding correlations between IL- 6 and MIP-2 at $6 \mathrm{~h}$ and neutrophils $24 \mathrm{~h}$ after endotoxin exposure. However, taken together, the current findings are indeed compatible with specific $\beta$ adrenoceptor stimulation causing a selective inhibitory effect on certain cytokine release from local cells in the airways in vivo. The findings also support that these effects subsequently result in an anti-inflammatory action on endotoxin-induced accumulation of neutrophils in the airways. Because it is known that IL-6 plays an important role in endotoxin-induced neutrophil accumulation in mouse airways $[15,16,18,20]$, it is feasible that the demonstrated inhibition of IL-6 release at least in part accounts for the referred antiinflammatory effect of $\beta$-adrenoceptor stimulation. However, the involvement of additional neutrophil-mobilising factors, apart from MIP-2, cannot be excluded. 

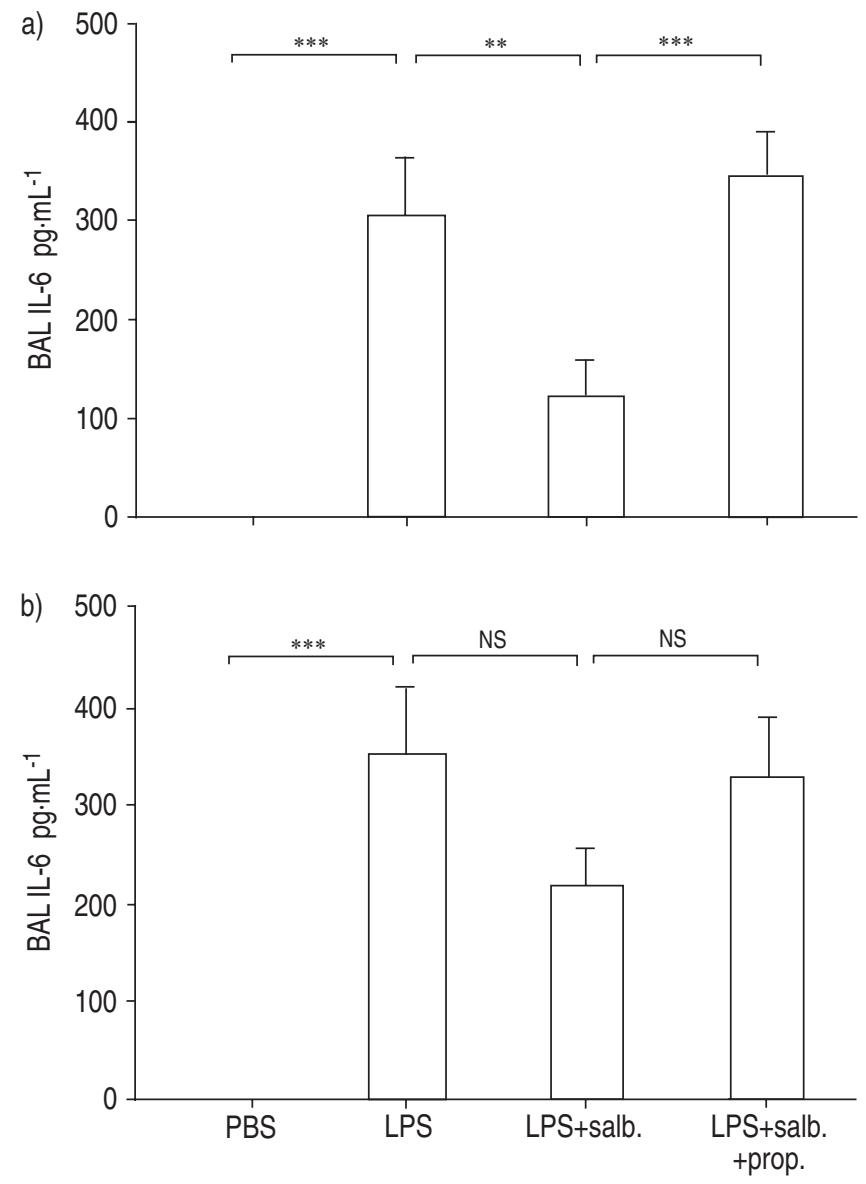

Fig. 5.-Effect of pretreatment intraperitoneally with propranolol (prop.; $\left.50 \mathrm{mg} \cdot \mathrm{kg}^{-1}\right)$ or its vehicle $(0.5 \mathrm{~mL}$ phosphate-buffered saline (PBS)) prior to treatment with salbutamol (salb.; $2.5 \mathrm{fMol}$ ) or its vehicle ( $25 \mu \mathrm{L}$ PBS) intranasally (i.n.), followed by exposure to endotoxin (LPS: $10 \mu \mathrm{g})$ or its vehicle $(25 \mu \mathrm{L}$ PBS) i.n., on the concentration of interleukin-6 (IL-6) in cell-free bronchoalveolar lavage (BAL) fluid from mice. BAL fluid was collected a) $6 \mathrm{~h}$ and b) $24 \mathrm{~h}$ after endotoxin exposure. Data presented as mean with error bars showing SE. NS: nonsignificant. ${ }^{* *}: \mathrm{p}<0.01 ; * * *: \mathrm{p}<0.001 . \mathrm{n}=10$ (a). $\mathrm{n}=17$ for PBS, $n=29$ for LPS and LPS+salb., $n=28$ for LPS+salb.+prop. (b).

Macrophages are believed to play a central role in responses to endotoxin exposure and, of particular interest, they release IL-6 in response to this type of exposure [13, 21-23]. In support of such a role, and in line with data from the current study, the endotoxin-induced release of IL-6 from a human macrophage-like cell line and from rat renal macrophages is also inhibited by $\beta$-adrenoceptor stimulation $[13,22,24]$. The release of free-oxygen radicals from human alveolar macrophages can also be inhibited by $\beta$-adrenoceptor stimulation [25]. Hypothetically, the cellular targets for $\beta$ adrenoceptor stimulation may thus include IL-6 from macrophages. However, it can be speculated that these targets also include bronchial epithelial cells and venous endothelial cells, because these cell types can release IL- 6 under certain conditions $[26,27]$. The role of lung fibroblasts is more uncertain in this context, since at least in rat cardiac fibroblasts, $\beta$-adrenoceptor stimulation leads to a substantially increased release of IL-6 [28, 29].

It is noteworthy that the concentration of IL-6 displayed a relatively strong correlation with BAL neutrophils harvested $6 \mathrm{~h}$ after endotoxin exposure, whereas a weaker correlation was observed for the IL-8 correlate MIP-2. This observation is indeed in line with the previously demonstrated inhibitory
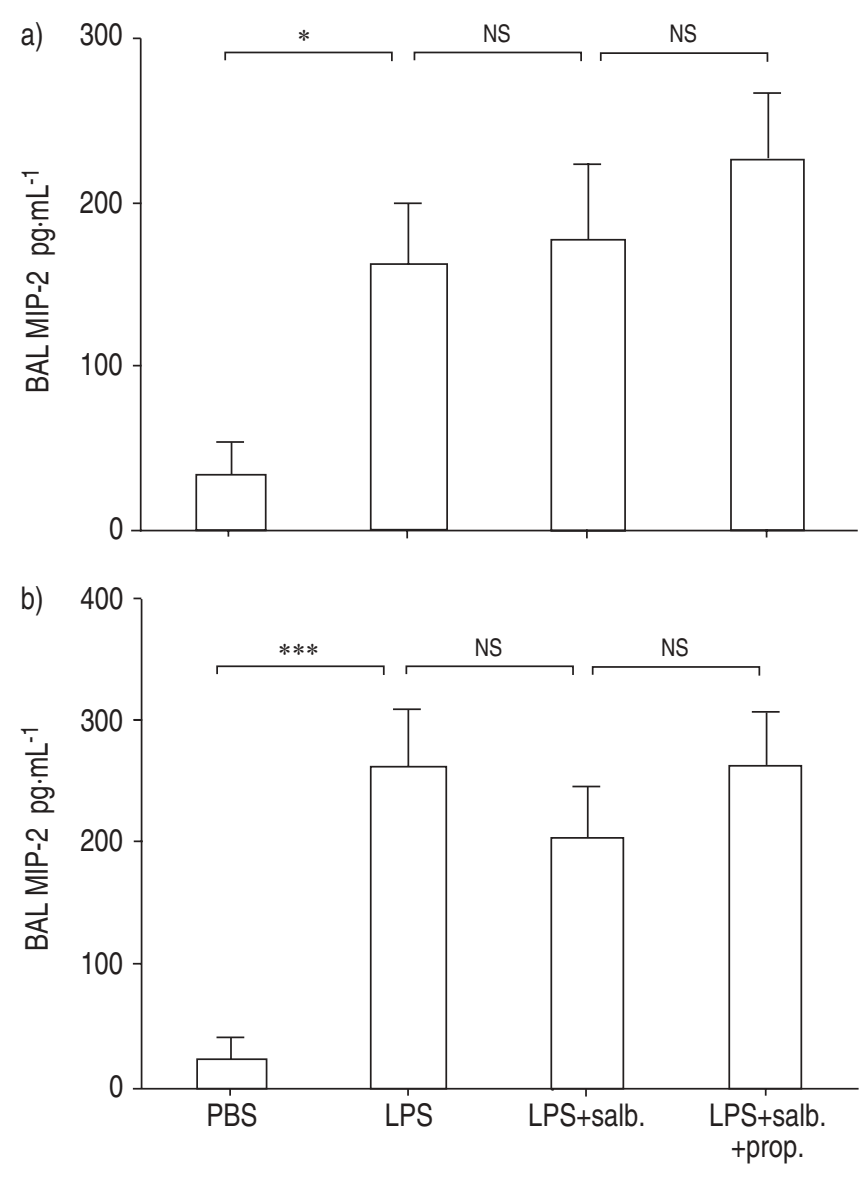

Fig. 6. - Effect of pretreatment with propranolol (prop.; $50 \mathrm{mg} \cdot \mathrm{kg}^{-1}$ ) or its vehicle $(0.5 \mathrm{~mL}$ phosphate buffered saline (PBS)) intranasally (i.n.) prior to treatment with salbutamol (salb.; $2.5 \mathrm{fMol}$ ) i.n., followed by exposure to endotoxin (LPS; $10 \mu \mathrm{g})$ or its vehicle $(25 \mu \mathrm{L}$ PBS), on the concentration of macrophage inflammatory protein (MIP)-2 in cell-free bronchoalveolar lavage (BAL) fluid from mice. BAL fluid was collected a) $6 \mathrm{~h}$ and b) $24 \mathrm{~h}$ after endotoxin exposure. Data presented as mean with error bars showing SE. NS: nonsignificant. $*: \mathrm{p}<0.05$; ***: $\mathrm{p}<0.001 . \mathrm{n}=10$ (a). $\mathrm{n}=16$ for PBS, $\mathrm{n}=30$ for LPS, $\mathrm{n}=29$ for LPS+salb., $n=28$ for LPS+salb.+prop. (b).

effect of a neutralising anti-IL-6 antibody on endotoxininduced neutrophil accumulation in the current authors mouse airway model [18]. Taken together, these findings forward local IL-6, besides C-X-C chemokines, such as MIP2 , as an important determinant for early neutrophil accumulation but it remains to be confirmed whether this is also true in man.

It is of particular interest that the current study demonstrates that there may be a substantial time lag between the local stimulation of $\beta$-adrenoceptors and its functional outcome for the accumulation of inflammatory cells in vivo, in this case the inhibition of accumulated neutrophils in the airways. This "anti-inflammatory" effect is much more sustained than that anticipated from salbutamol's effect on airway smooth muscle in vitro or its bronchodilatory effect in vivo [29-32]. Even though the current study forwards IL-6 as an important target mediator for salbutamol, the specific molecular mechanisms behind salbutamol's sustained "anti-inflammatory" effect remain unknown. Indeed, it is known that the direct effect of salbutamol on cyclic AMP is coupled immediately to the control of contractile force in airway smooth muscle, with very short time delay [12, 30-32]. The current authors speculate that the case may be very 

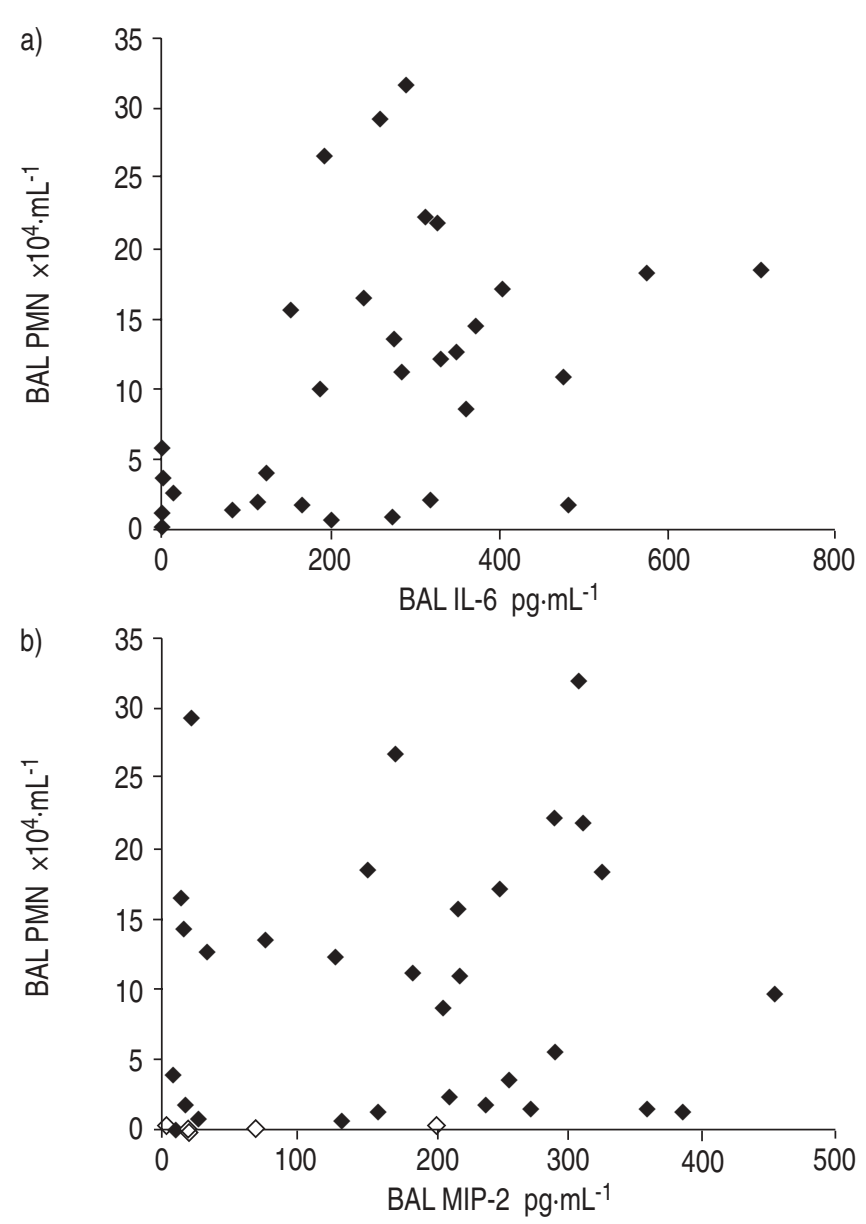

Fig. 7.-Correlation between number of neutrophils (PMN) and concentration of a) interleukin (IL)-6 (Spearman rank correlation: $\mathrm{Rho}=0.7, \mathrm{p}<0.0001, \mathrm{n}=40$ ) and $\mathrm{b}$ ) macrophage inflammatory protein (MIP)-2 (Spearman rank correlation: $\mathrm{Rho}=0.5, \mathrm{p}=0.004, \mathrm{n}=40$ ) in bronchoalveolar lavage (BAL) fluid from mice exposed to endotoxin $(10 \mu \mathrm{g}, \diamond)$ or its vehicle $(25 \mu \mathrm{L}$ PBS, $\diamond)$ intranasally (i.n.). Some mice were pretreated either with the $\beta$-adrenoceptor antagonist propranolol $\left(50 \mathrm{mg} \cdot \mathrm{kg}^{-1}\right)$ intraperitoneally (i.p.) plus salbutamol (2.5 fMol) i.n.,; or the vehicle of propranolol $(0.5 \mathrm{~mL}$ PBS) i.p. plus salbutamol $(2.5 \mathrm{fMol})$ i.n.; or the vehicle of propranolol $(0.5 \mathrm{~mL}$ PBS) i.p. plus the vehicle of salbutamol ( $25 \mu \mathrm{L}$ PBS $)$ i.n. prior to endotoxin exposure i.n. BAL fluid was collected $6 \mathrm{~h}$ after exposure to endotoxin or its vehicle.

different when it comes to the mechanistic coupling of a transient increase in cyclic AMP to the recruitment of inflammatory cells, the latter most likely being a complex series of events involving an altered production and release of cytokines from cells residing in the airways. At present, there are no in vivo data clarifying these events. However, there are in vitro data, showing for example that the induced release of IL-6 protein "peaks" after $12 \mathrm{~h}$, or even later, as assessed in "macrophage-like" cells [13]. In the current study the inhibitory effect of a $\beta$-adrenoceptor agonist on this IL-6 release in vitro is evident up to at least $24 \mathrm{~h}$ after administration. For the neutrophil-mobilising cytokine GM-CSF, the induced release may peak even later than $96 \mathrm{~h}$, as indicated in human airway smooth muscle in vitro [12]. For this GM-CSF release, the inhibitory effect of a $\beta$-adrenoceptor agonist is evident from $24 \mathrm{~h}$. To this substantial period of time, the time delay between the local release of IL-6 and its functional outcome for neutrophils entering lungs should be considered. For induced changes in total lung neutrophil counts, this time delay may exceed $12 \mathrm{~h}$ after IL-6 is given systemically, as indicated in rabbits in vivo [20]. For newly formed neutrophils in the same in vivo model, it constitutes $\sim 24 \mathrm{~h}$ [20]. Hypothetically, the local release of IL-6 in the lungs may need an even longer time than this, before the number of lung neutrophils is affected. This is because local IL-6 probably has to diffuse from the lung to the pool of neutrophils (blood vessels and bone marrow), prior to affecting neutrophil recruitment into the local tissue in vivo. Thus, it seems mechanistically feasible that $\beta$-adrenoceptor stimulation leads to a transient effect on intracellular cyclic AMP that subsequently causes an altered cytokine transcription and release several hours later, after the immediate effect on cyclic AMP is gone. The altered cytokine release, in turn, causes an impact on the accumulation of neutrophils many hours, possibly days, later. This sustained anti-inflammatory effect may in this way appear substantially later than the bronchodilatory effect of salbutamol, even though the bronchodilatory effect may be present as late as 9-10 h after administration in patients with asthma [33, 34]. Clearly, new mechanistic studies are motivated to further elucidate the molecular events behind this phenomenon.

To some extent, the current demonstration of an inhibitory action on endotoxin-induced neutrophil accumulation being exerted by salbutamol in vivo questions the results from previous studies on human airway smooth muscle cells, bronchial epithelial cells and monocytes in vitro, cells that all demonstrate a clear increase in the release of the human correlate to MIP-2, IL-8, after $\beta$-adrenoceptor stimulation [7-11]. It remains unclear whether this discrepancy can be attributed to the fact that certain in vitro phenomena lack an in vivo correlate or whether the referred in vitro findings on IL-8 have more bearing for conditions during chronic $\beta$ adrenoceptor stimulation in airways in vivo.

It could be argued that the local, anti-inflammatory effect of salbutamol in the current study is contradictory to previous in vivo studies indicating a corresponding "pro-inflammatory" action of $\beta$-adrenoceptor agonists [2-5]. However, the current authors believe that this may be explained in terms of differences in airway models. One such difference is the "immunological setting"; several of the referred studies have examined a "T-helper cell type 2" (Th2) setting whereas the currents study was conducted in a "T-helper cell type 1" (Th1) setting. Another such difference of potential importance is whether the $\beta$-adrenoceptor agonist was administered once or repeatedly.

I.n. treatment with salbutamol did indeed exert a moderate increasing effect on the relative number of neutrophils in venous blood, in line with previous data on the role of endogenous catecholamines and $\beta$-adrenoceptor stimulation in rats in vivo [6]. In the current study, this phenomenon tended to be of greater magnitude in naive, unexposed mice than in endotoxin-exposed mice. The same pattern was also observed when the absolute number of neutrophils (i.e. concentration) was determined in venous blood (data not shown). The findings are thus compatible with local $\beta$ adrenoceptor stimulation causing a systemic effect. However, taken together, data from the current study do not indicate that this moderate increase in blood neutrophils is detrimental when local exposure to a proinflammatory stimulus (i.e. endotoxin) occurs. Because it is known that $\beta$-adrenoceptor stimulation tends to decrease neutrophil adhesion and certain neutrophil-related adhesion molecules in vascular endothelial cells in vitro, it is possible that salbutamol prevents neutrophils from entering the airways and that this per se leads to a secondary increase in circulating neutrophils [35].

In conclusion, this study on mice indicates that local $\beta$-adrenoceptor stimulation can prevent endotoxin-induced accumulation of neutrophils in vivo, at a time point substantially later than that expected from the time course 
of the $\beta$-adrenoceptor's bronchodilatory effect. This potentially anti-inflammatory effect may in part be due to a decrease in the local concentration of interleukin- 6 and it is observed in spite of $\beta$-adrenoceptor stimulation causing a moderate increase in the relative number of neutrophils in venous blood. New in vivo studies are needed to determine whether or not repeated $\beta$-adrenoceptor stimulation leads to similar consequences for neutrophil accumulation in the airways and what implications this may have for humans, in particular for the treatment of obstructive pulmonary disease.

\section{References}

1. Lindén A. Rationale for targeting interleukin-17 in the lungs. Current Opin Invest Drugs 2003; 4: 1304-1312.

2. Cockroft DW, McParland CP, Britto SA, Swystun VA, Rutherford BC. Regular inhaled salbutamol and airway responsiveness to allergen. Lancet 1993; 342: 833-837.

3. Cockroft DW, O'Byrne PM, Swystun VA, Bhagat R. Regular use of albuterol and the allergen-induced late asthmatic response. J Allergy Clin Immunol 1995; 96: 44 49.

4. Innan MD, O'Byrne PM. The effect of regular inhaled albuterol on exercise-induced bronchoconstriction. $\mathrm{Am}$ J Respir Crit Care Med 1996; 153: 65-69.

5. Aldridge RE, Hancox RJ, Robin Taylor D, et al. Effects of terbutaline and budesonide on sputum cells and bronchial hyperresponsiveness in asthma. Am J Respir Crit Care Med 2000; 161: 1459-1464.

6. Altenburg SP, Bozza PT, Martins MA, et al. Adrenergic modulation of the blood neutrophilia induced by platelet activating factors in rats. Eur J Pharmacol 1994; 256: 45-49.

7. Kavelaars A, Van De Pol M, Ziljstra J, Heijnen CJ. Beta2adrenergic activation enhances interleukin- 8 production by human monocytes. J Neuroimmunol 1997; 77: 211-216.

8. Korn SH, Jerre A, Brattsand R. Effects of formoterol and budesonide on GM-CSF and IL-8 secretion by triggered human bronchial epithelial cells. Eur Respir J 2001; 17: 1070-1077.

9. Lindén A. Increased interleukin-8 release by beta-adrenoceptor activation in human transformed bronchial epithelial cells. Br J Pharmacol 1996; 119: 402.

10. Pang L, Knox AJ. Synergistic inhibition by beta ${ }_{2}$-agonists and corticosteroids on tumor necrosis factor-a-induced interleukin-8 release from cultured human airway smooth muscle cells. Am J Respir Cell Mol Biol 2000; 23: 79-85.

11. Prause O, Laan M, Lötvall J, Lindén A. Pharmacological modulation of interleukin-17-induced GCP-2-, GRO- $\alpha$ - and interleukin-8-release in human bronchial epithelial cells. Eur J Pharmacol 2003; 462: 193-198.

12. Hallsworth MP, Twort CHC, Lee TH, Hirst SJ. $\beta_{2^{-}}$ adrenoceptor agonists inhibit release of eosinophil-activating cytokines from human airway smooth muscle cells. $\mathrm{Br}$ J Pharmacol 2001; 132: 729-741.

13. Izebouds CA, Monshouwer $\mathrm{M}$, Van Miert ASJPAM, Witkamp RF. The beta-adrenoceptor agonist clenbuterol is a potent inhibitor of the LPS-induced production of TNFalpha and IL-6 in vitro and in vivo. Inflamm Res 1999; 48: 497-502.

14. Appelberg R. Macrophage inflammatory proteins MIP-1 and MIP-2 are involved in $\mathrm{T}$ cell-mediated neutrophil recruitment. J Leukoc Biol 1992; 52: 303-306.

15. Bank U, Reinhold D, Kunz D, et al. Effects of interleukin-6 (IL-6) and transforming growth factor-beta (TGF-beta) on neutrophil elastase release. Inflammation 1995; 19: 83-99.

16. Biffl WL, Moore EE, Moore FA, Barnett CC. Interleukin-6 suppression of neutrophil apoptosis is neutrophil concentration dependent. J Leukoc Biol 1995; 58: 582-584.

17. Frevert CW, Farone A, Danaeaee H, Paulauskis JD, Kobzik L. Functional characterization of rat macrophage inflammatory protein-2. Inflammation 1995; 19: 133-142.

18. Miyamoto M, Prause O, Laan M, Sjöstrand M, Lötvall J, Lindén A. Endogenous IL-17 as a mediator of airway neutrophilia caused by endotoxin exposure in mouse airways. J Immunology 2003; 170: 4665-4672.

19. Rovai LE, Herschman HR, Smith JB. The murine neutrophil-chemoattractant chemokines LIX, KC, and MIP-2 have distinct induction kinetics, tissue distributions, and tissue specific sensitivities to glucocorticoid regulation in endotoxemia. J Leukoc Biol 1998; 64: 494-502.

20. Suwa T, Hogg JC, Klut ME, Hards J, Eeden SF. Interleukin6 changes deformability of neutrophils and induces their sequestration in the lung. Am J Crit Care Med 2001; 163 : 970-976.

21. Sitkauskiene B, Sakalauskas R, Malakauskas K, Lötvall J. Reversibility to a beta ${ }_{2}$-agonist in COPD: relationship to atopy and neutrophil activation. Resp Med 2003; 97: 591598.

22. Izeboud CA, Mocking JA, Monshouwer M, Van Miert AS, Witkamp RF. Participation of beta-adrenergic receptors on macrophages in the modulation of LPS-induced cytokine release. J Recept Signal Transduct Res 1999; 19: 191-202.

23. Persoons JHA, Schornages K, Tilders FFH, De Vente J, Berkenbosch F, Kraal G. Alveolar macrophages autoregulate IL-1 and IL-6 production by endogenous nitric oxide. Am J Respir Cell Mol Biol 1996; 14: 272-278.

24. Nakamura A, Johns EJ, Imaizumi A, Yanagawa Y, Koshaka T. Modulation of interleukin- 6 by beta -adrenoceptor $^{-}$ in endotoxin-stimulated renal macrophage cells. Kidney Int 1999; 56: 839-849.

25. Capelli A, Lusuardi M, Carli S, Zaccaria S, Trombetta N, Donner CF. In vitro effect of beta ${ }_{2}$-agonists on bacterial killing and superoxide anion (O2-) release from alveolar macrophages of patients with chronic bronchitis. Chest 1993; 104: 481-486.

26. Hooper WC, Phillips DJ, Renshaw MA, Evatt BL, Benson JM. The up-regulation of IL-6 and IL-8 in human endothelial cells by activated protein C. J Immunology 1998; 161: 2567-2573.

27. Laan M, Lötvall J, Chung KF, Lindén A. IL-17-induced cytokine release in human bronchial epithelial cells in vitro: role of mitogen-activated protein (MAP) kinases. $\mathrm{Br}$ J Pharmacol 2001; 133: 200-206.

28. Burger A, Benicke M, Deten A, Zimmer H-G. Catecholamines stimulate interleukin-6 synthesis in rat cardiac fibroblasts. Am J Physiol Heart Circ Physiol 2001; 281: 14 21.

29. Zitnik RJ, Whiting NL, Elias JA. Glucocorticoid inhibition of interleukin-6 production by human lung fibroblasts: Evidence for transcriptional and post-transcriptional mechanisms. Am J Respir Cell Mol Biol 1994; 10: 643-650.

30. Anderson $\mathrm{P}$, Lötvall $\mathrm{J}$, Lindén A. Relaxation kinetics of formoterol and salmeterol in the guinea pig trachea in vitro. Lung 1996; 174: 159-170.

31. Nials AT, Coleman RA, Johnson M, Magnussen H, Rabe $\mathrm{KF}$, Vardey CJ. Effects of $\beta$-adrencoeptor agonists in human bronchial smooth muscle. Br J Pharmacol 1993; 110: 11121116.

32. Rabe K, Lindén A. Mechanisms of long duration of action of inhaled long-acting beta ${ }_{2}$-adrencoeptor agonists. In: Pauwels R, O'Byrne $\mathrm{P}$, eds. Beta ${ }_{2}$-agonists in asthma treatment. New York, Marcel Dekker, 1997; pp. 131-154.

33. Palmqvist M, Balder B, Löwhagen O, Melander B, Svedmyr $\mathrm{N}$, Wåhlander L. Late asthmatic reaction decreased after pre-treatment with salbutamol and formoterol, a new long-acting $\beta_{2}$-agonist. $J$ All Clin Immunol 1992; 89: 844849.

34. Wallin A, Sandstrom T, Rosenhall L, Melander B. Time course and duration of bronchodilation with formoterol dry powder in patients with stable asthma. Thorax 1993; 48: 611614.

35. Blease K, Burke-Gaffney A, Hellewell PG. Modulation of cell adhesion molecule expression and function on human lung microvascular endothelial cells by inhibition of phosphodiesterase 3 and 4. Br J Pharmacol 1998; 124: 229-237. 